\title{
Feed Plate and Feed Adsorbent Temperature Optimisation of Distillation - Adsorption Process to Produce Absolute Ethanol
}

\author{
Fadlilatul Taufany ${ }^{1}$, Nonot Soewarno ${ }^{1}$, Koko Yuwono ${ }^{1}$, Dimas Ardiyanta ${ }^{1}$, Melvina Eliana $^{1} \&$ Indi Raisa \\ Girsang $^{1}$ \\ ${ }^{1}$ Department of Chemical Engineering, Sepuluh Nopember Institute of Technology, Indonesia \\ Correspondence: Fadlilatul Taufany, Department of Chemical Engineering, Sepuluh Nopember Institute of \\ Technology, Surabaya, 60111, Indonesia. E-mail: taufany99@yahoo.com
}

Received: May 4, 2015

doi:10.5539/mas.v9n7p140
Accepted: June 5, 2015

Online Published: June 30, 2015

\begin{abstract}
Two subsequent separation processes are required to produce absolute ethanol (at least purity of $99.5 \% \mathrm{v} / \mathrm{v}$ ), namely the distillation and adsorption processes. Thus, it is important to find the optimum operation condition for those following processes. The aims of the present study are to optimize the feed plate of distillation and the temperature of feed adsorbent. This study is conducted using a continuous sieve tray distillation system with the number of 16 trays, the length-diameter ratio of 80.64, the reflux ratio of 3.5, and the feed with ethanol content of $10 \% \mathrm{v} / \mathrm{v}$ ethanol, which is produced via the fermentation process of molasses. To conduct the first aim of this study, the feed enters the distillation column with several of variable feed plate, i.e. 12,13,14, and 15. This feed plate location is calculated from the top of the column. On the other hand, the second aim of this study, is conducted using the subsequent combination of distillation and adsorbent columns, where the distillate (purity of ethanol around $95 \% \mathrm{v} / \mathrm{v}$ ) from the distillation column is then flowed into the adsorbent column with various feed adsorbent temperature, i.e. $80{ }^{\circ} \mathrm{C}, 90^{\circ} \mathrm{C}, 100{ }^{\circ} \mathrm{C}$, and $110{ }^{\circ} \mathrm{C}$, to be purified as an absolute ethanol. Here the adsorbent column is designed as a fix bed adsorption column with a molecular sieve of $3 \mathrm{~A}$ (zeolite) is used as an adsorbent for that purification process. Our results showed that the optimum feed plate is 14 , because at this plate the ethanol distillate has the highest content among those various variables. Meanwhile, the optimum temperature of feed adsorbent is $90^{\circ} \mathrm{C}$, which requires the least energy for the distillation - adsorption process, i.e. at $18691 \mathrm{~kJ} / \mathrm{kg}$ absolute ethanol. This primary study is expected to be an alternative way to optimize the operating condition of the sieve tray distillation-molecular sieve adsorption system by means of acquiring a minimum energy involving in the process to achieve the highest purity of ethanol.
\end{abstract}

Keywords: adsorption, distillation, ethanol, feed, plate, temperature

\section{Introduction}

Nowadays, absolute ethanol is one of the various types of biofuel produced and has became one of crisis energy solution as a renewable energy in worldwide. One of the relatively large potential manufactures of absolute ethanol is made from by-products of cane sugar industry, namely molasses. In ethanol-water distillation process, the existence of azeotropic point makes it difficult to get in a state of absolute ethanol (99.5\%) through normal distillation process. In order to achieve anhydrous ethanol, it requires an additional process that is known as dehydration process to remove the water content from its water content by using zeolite adsorbent (Baeyens, J., et al., 2015; Gupta, A., et al., 2015; Kumar, S., et al., 2010; Kaminski, W., et al., 2008).

Various studies have been conducted in the field of separation of ethanol-water mixture via distillation-adsorption process. Sieve tray distillation is widely used for the separation of that type of liquid mixture, due to the advantages of its affordable cost and simplicity in design (Van Winkle, M., 1961; McCabe, W. L., 2001; Zuiderweg, F. J., 1982). In addition, Syeda, S. R., et al., found that the overall efficiency of sieve-tray distillation, in term of the purity of ethanol destillate is strongly influenced on the location of the feed plate. Thus, it is important to find an optimum feed plate location in particular design of sieve tray distillation column. To date, this challenge has only been studied by a modelling (Viswanathan, J. Grossmannt, I. E., 1993).

On the other hand, the consecutive process of distillation by means of removing its water content generally employs the adsorption process in vapour phase by using solid adsorbents. Taking examples, Wang, Y., et al. studied the separation of ethanol/water azeotrope by using compound starch-based adsorbents for dehydrating 
ethanol. Interestingly, Al-Asheh, S. et al. studied the use of various molecular sieve adsorbents to dehydrate the ethanol-water mixture and to compare each other. They found that a molecular sieve $3 \AA$ is the best solid adsorbent than that of $4 \AA$ and $5 \AA$ to adsorb the water content. Their finding is also in a good agreement with that of study being conducted by Sowerby, B. and Crittenden, B. D. As a result, the molecular sieve of $3 \AA$ adsorbent is widely used in ethanol purification form its water content (Chen, W. C., et al., 2014; Simo, M., et al., 2009).

In combination of distillation-adsoprtion process, Kumar, S. et al. has reported a method to calculate the energy consumption for the distillation - adsorption process that particularly used a solid adsorbent. However to the best of our knowledges, the studies on finding optimal condition for the particular water adsorption from ethanol using molecular sieve $3 \AA$ in gas phase, has not been reported yet. Therefore, it encourages us to conduct a study with the aim to produce anhydrous ethanol at a lowest total energy involved in sieve tray distillation-adsorption process, by means of finding an optimum condition from the feed plate location of 16 trays and from that of the molecular sieve $3 \AA$ packed bed adsorption.

\section{Method}

\subsection{Apparatus and Procedures}

The procedure of this study is initiated with the fermentation of molasses using a particular yeast of Saccharomyces cerevisiae in a mixture media of molasses-water with its ratio of $1: 3$ (i.e. $15 \mathrm{~L}: 45 \mathrm{~L}$ ) to form low-grade ethanol. Here the urea and yeast are added with the amount of $0.5 \%(70 \mathrm{~g})$ and $0.2 \%(11 \mathrm{~g})$ of total glucose, respectively. This fermentation of molasses proceeds in anaerobic condition for approximate period of 66 hours, which can be also indicated from the formation of $\mathrm{CO}_{2}$ bubbles. Before this low-grade ethanol is distillated, the ethanol content of feed is analyzed using alcoholmeter. After this, the distillation of low-grade ethanol is carried out in atmospheric condition using sieve tray distillation column, which totally consists of 16 trays. This low-grade ethanol is distillated with the variables of feed plate position of $12^{\text {th }}$, the $13^{\text {th }}$, the $14^{\text {th }}$, and the $15^{\text {th }}$ plate calculated from the top of the sieve tray column. After the distillate is produced, the ethanol contents in the product and the amount of energy consumptions is measured. The produced ethanol distillate is then purified from its water content by using a solid adsorbent (i.e. molecular sieve $3 \AA$ ) to produce anhydrous ethanol. At this step, the variables of feed temperatures of produced distillate ethanol are $80,90,100$, or $110{ }^{\circ} \mathrm{C}$. The ethanol content from the adsorption effluent is measured using alcoholmeter, while the amount of energy consumption during the adsorption process is measured using $\mathrm{kWh}$-meter. The overall procedure of this study and its apparatus are schematically shown in Figure 1 and Figure 2, respectively.

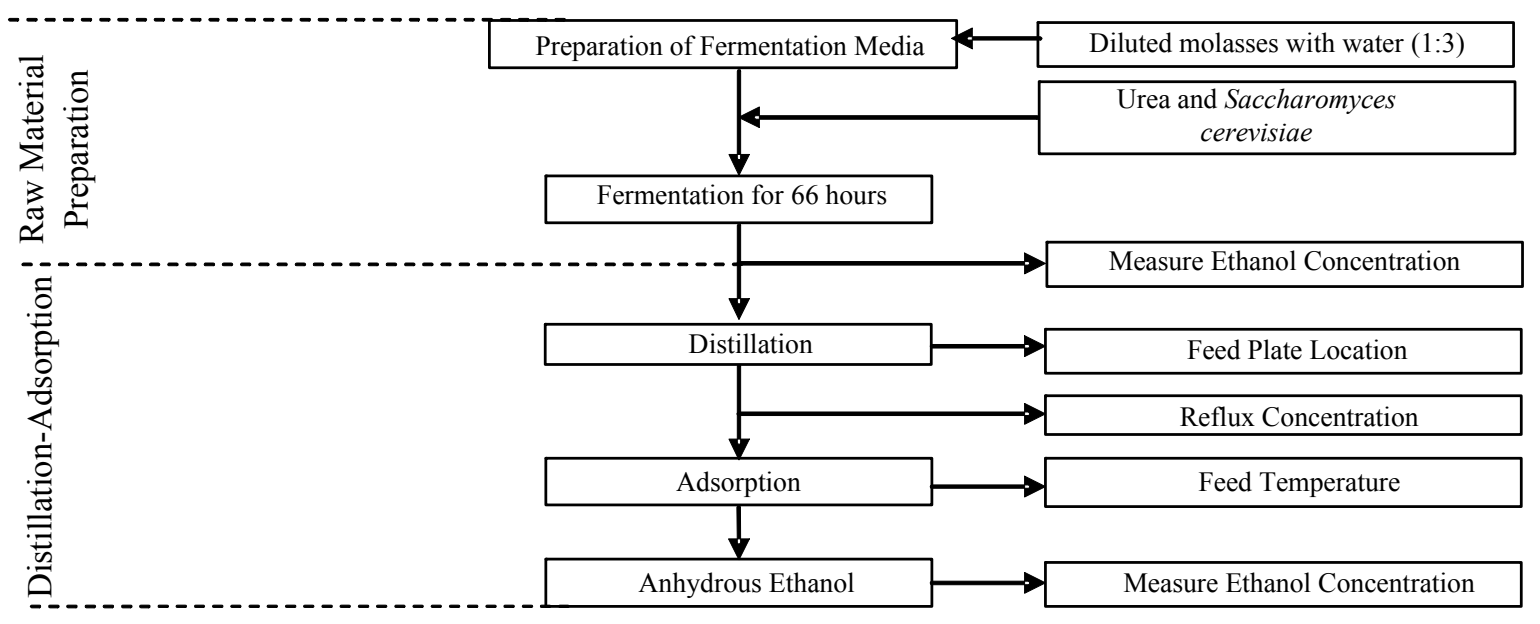

Figure 1. Flowchart of showing the procedure of research 


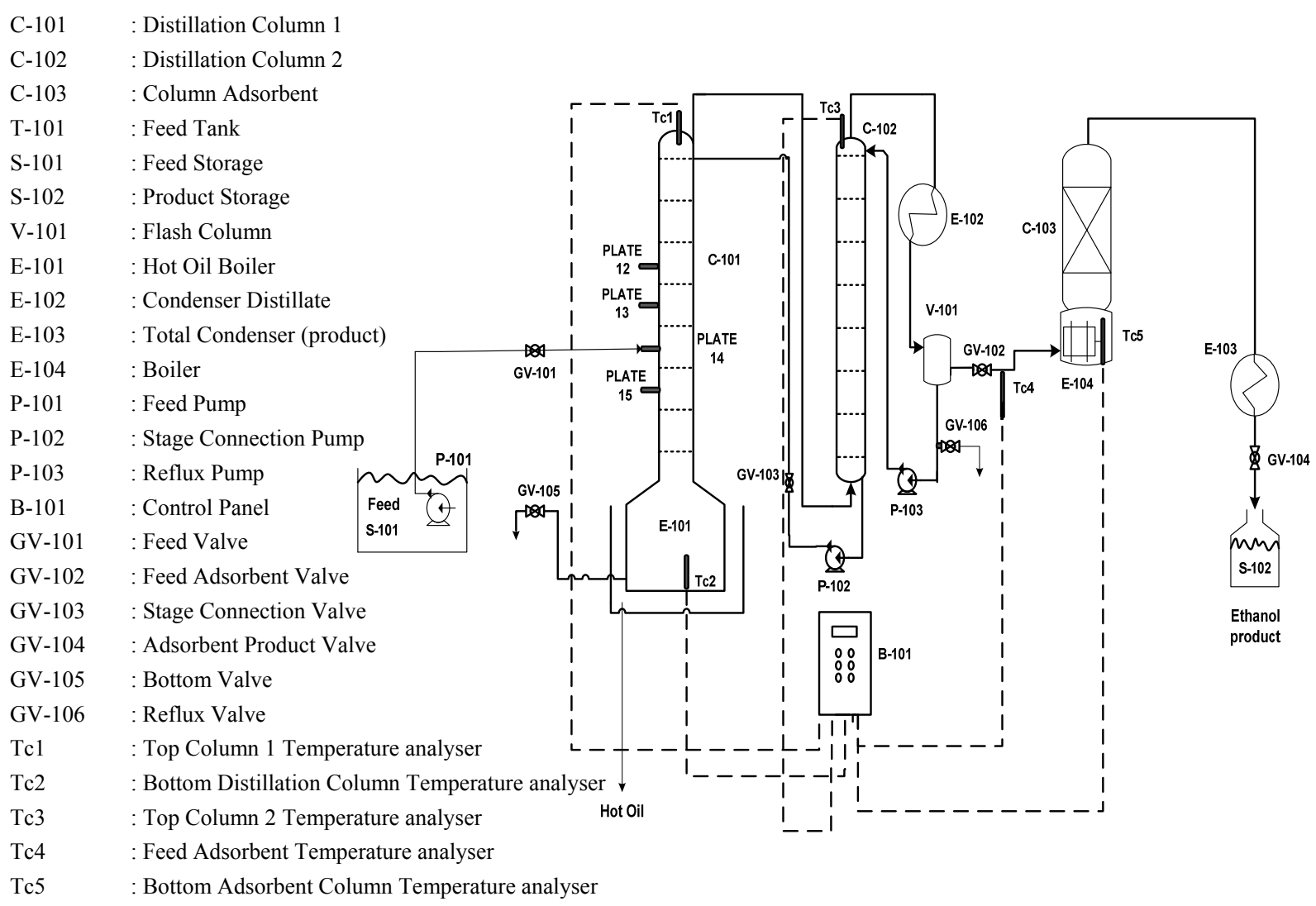

Figure 2. Schematic Diagram of the experimental apparatus

\section{Results and Discussion}

\subsection{Feed Plate Position in Distillation Process}

As shown in Figure 3, the highest content of ethanol is obtained when low-grade ethanol feed flowing through the $14^{\text {th }}$ plate, which is $92 \% \mathrm{v} / \mathrm{v}$. This can be explained as follows, when the feed pour into the distillation column through other position of plates, the equilibrium of vapour - liquid has not taken place yet, thus the separation process is not immediately occurred. Instead, when the feed stream through the $14^{\text {th }}$ plate, the separation process takes place immediately due to the temperature and composition of feed corresponding to the temperature and composition in the $14^{\text {th }}$ plate (McCabe, W. L., 2001).

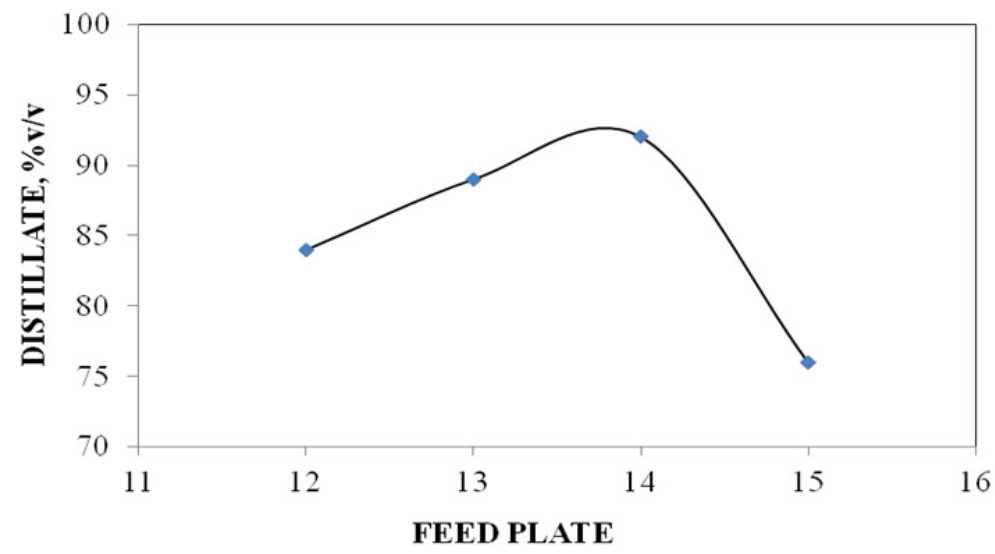

Figure 3. Correlation between ethanol concentration of distillate and number of feed plate 


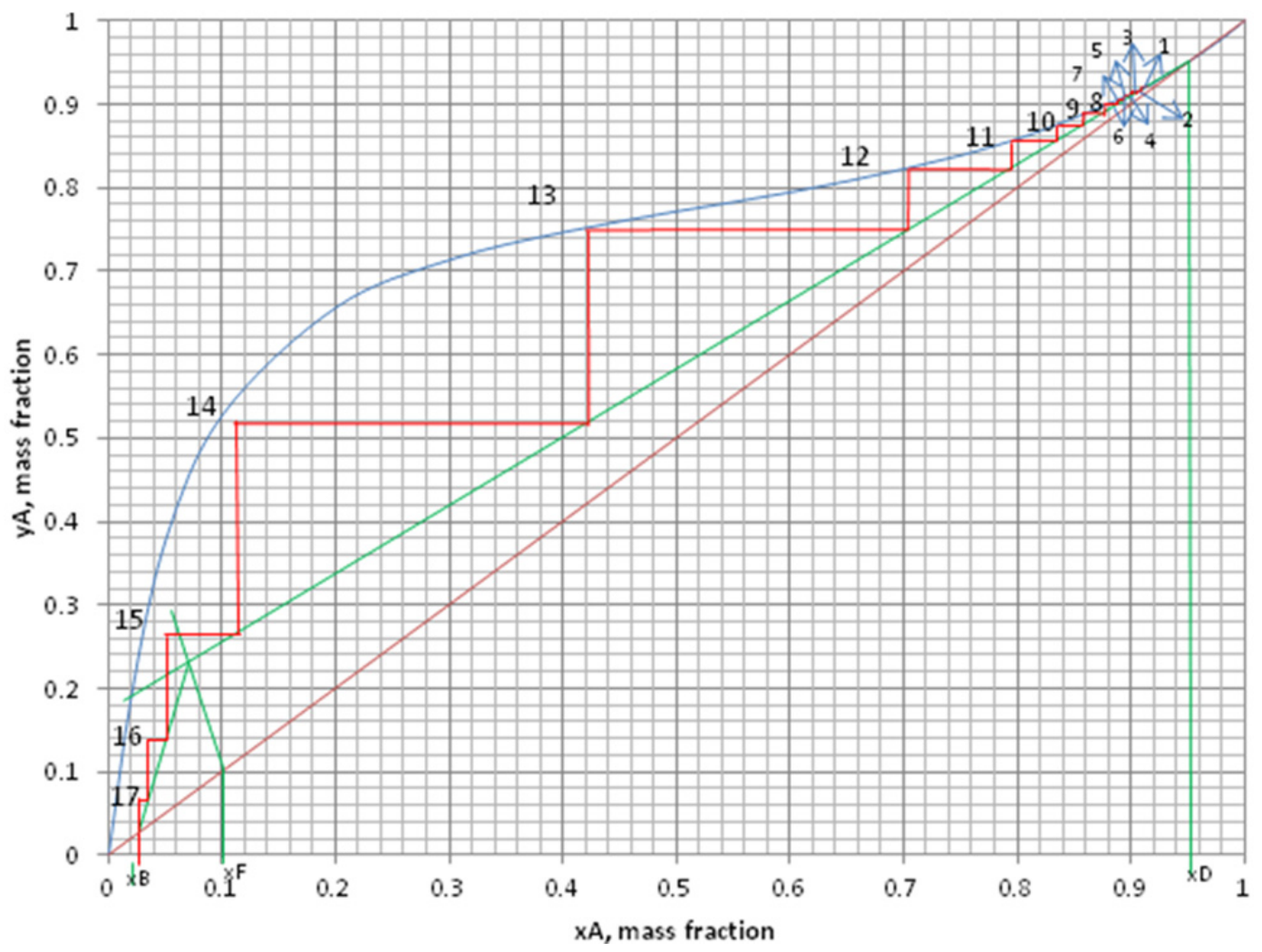

Figure 4 . The effect of placement feed on the $15^{\text {th }}$ plate

The placement of low-grade ethanol feed at a lower feed plate, for example, on the $15^{\text {th }}$ plate will increase the number of plate on rectifying section that is shown in Figure 4. On this plate, separation process occurred slightly inconsequence of the small mass transfer as a driving force. Likewise, the placement of feed pouring through the above of optimum plate will cause the same effect (McCabe, W. L., 2001).

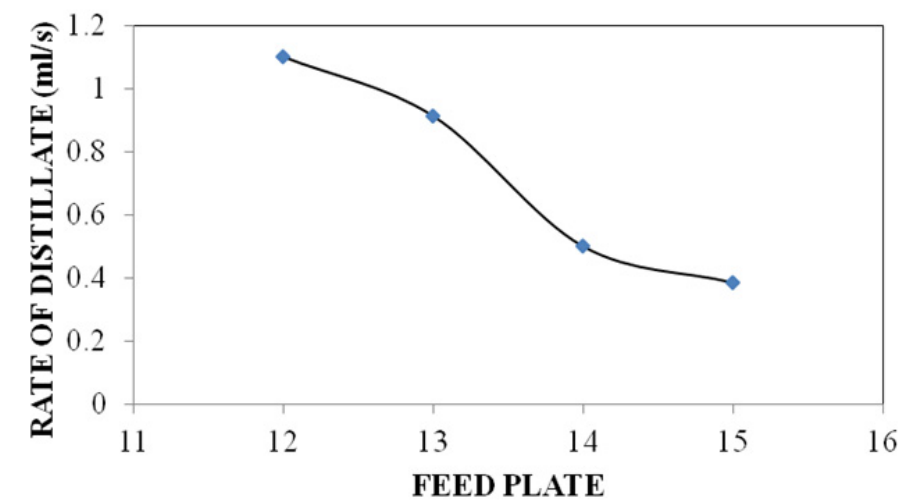

Figure 5. Correlation between distillate rate and feed plate disposition

It can be seen from Figure 5, the highest ethanol distillate rate is obtained when the feed stream is flowed through the $12^{\text {th }}$ plate, which is at $1.1 \mathrm{ml}$ per second. This is due to the increasing of contact between liquid of feed and vapour of reboiler when feed pour into the column, therefore the large amount of liquid phase is carried upward by the vapour phase. 


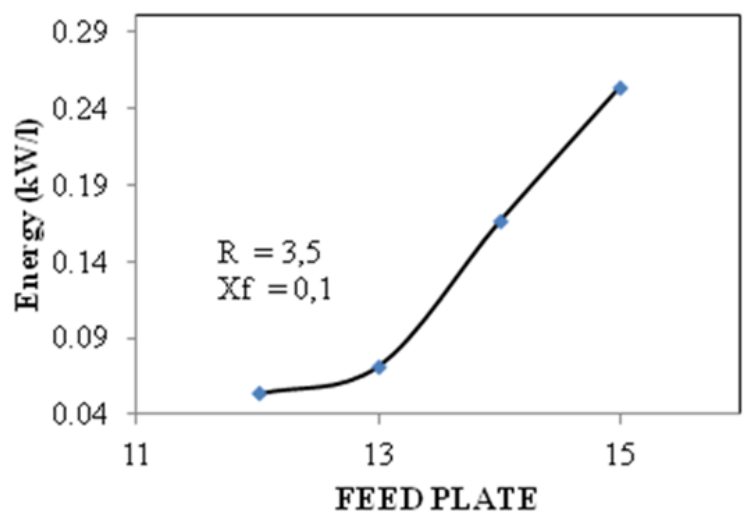

Figure 6. Correlation between energy consumed and feed plate disposition

The highest amount of energy is consumed when the low-grade ethanol feed is poured through the $15^{\text {th }}$ plate, as can be seen in Figure 6. This phenomenon can be explained as follows: a lower position of feed plate that is entering through the column will result in heavier reboiler load. This is because at such a lower position, the feed of having temperature of. $30^{\circ} \mathrm{C}$ is directly heated into a reboiler. In contrary, a higher position of feed plate will result in lower consumed energy. This is because of the feed is contacted with a hot mixture of liquid-vapor from reboiler, therefore the feed temperature is quite enough hot to enter the reboiler (i.e. higher than $30{ }^{\circ} \mathrm{C}$ ), which makes the reboiler loads becomes lighter.

\subsection{Temperature of Feed in Adsorption Process}

In the consecutive step of distillation process of producing anhydrous ethanol, that is adsorption process, the ethanol distillate is initially boiled in a boiler and is then contacted with a molecular sieve of $3 \AA$ adsorbent in packed bed column, so that the adsorption process occurs in gas phase. In this study, we also conducted various operating condition of adsorption process in order to find its optimum condition by means of its consumed energy. Here, the temperature of boiled ethanol distillate is varied from 80 to $110^{\circ} \mathrm{C}$, at different location of feed plate (i.e. feed plate of $12^{\text {th }}, 13^{\text {th }}, 14^{\text {th }}$, and $15^{\text {th }}$ ). At a particular temperature of boiled ethanol distillate, breaktrough time curve is obtained. The results from the above mentioned various conditions, either of its feed temperature and feed plate location, are presented in Figures 7 to 10.

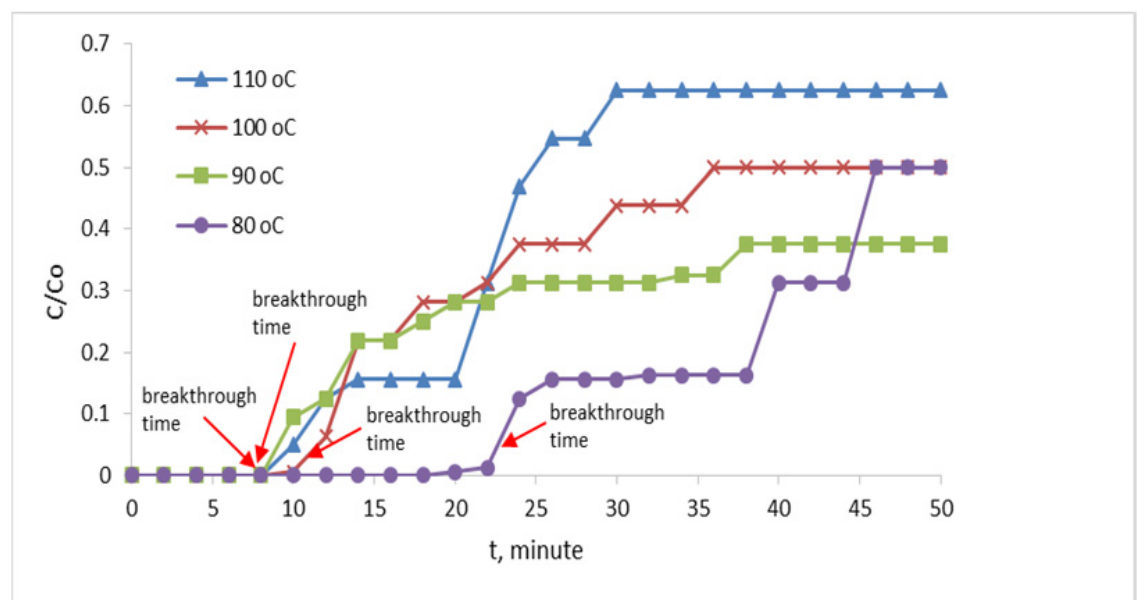

Figure 7. Breakthrough time curve in adsorption process with the ethanol content of feed at $84 \% \mathrm{v} / \mathrm{v}$ and the feed plate location in distillation process at $12^{\text {th }}$ plate 


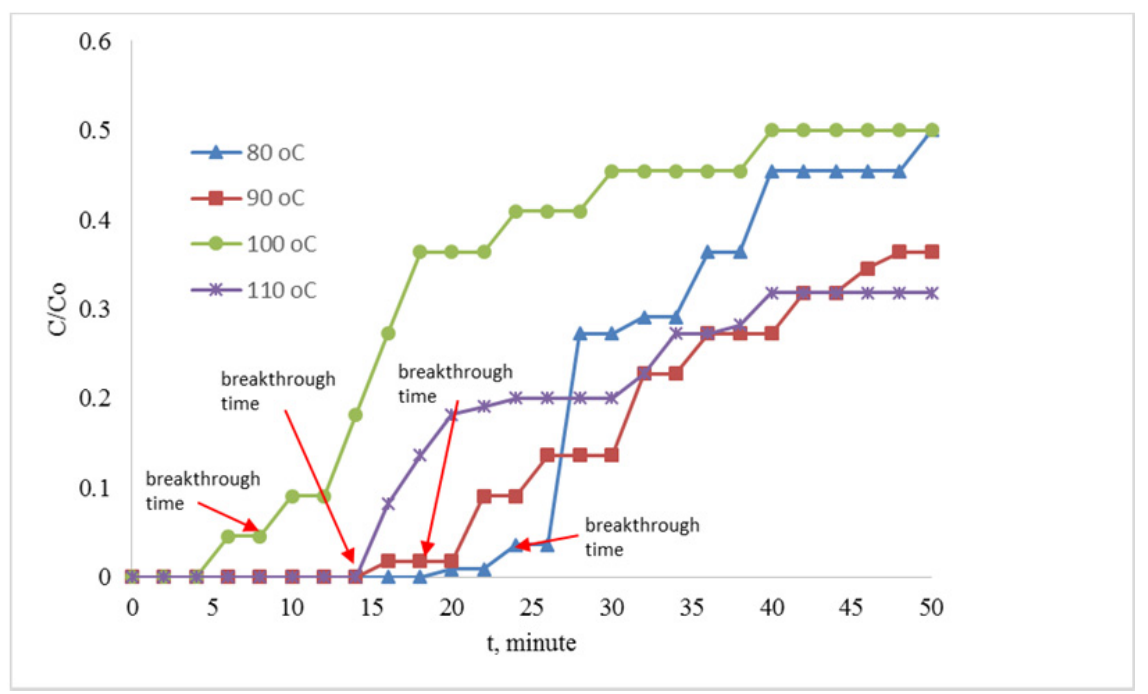

Figure 8. Breakthrough time curve in adsorption process with the ethanol content of feed at $89 \% \mathrm{v} / \mathrm{v}$ and the feed plate in distillation process at the $13^{\text {th }}$ plate

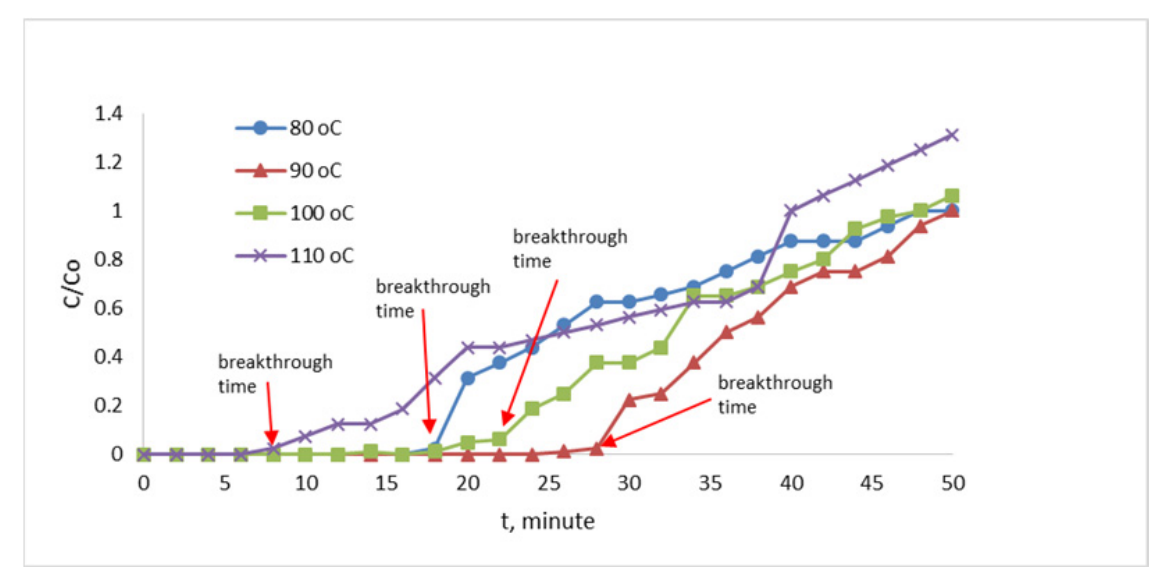

Figure 9. Breakthrough time curve in adsorption process with the ethanol content of feed at $92 \% \mathrm{v} / \mathrm{v}$ and the feed plate in distillation process at the $14^{\text {th }}$ plate

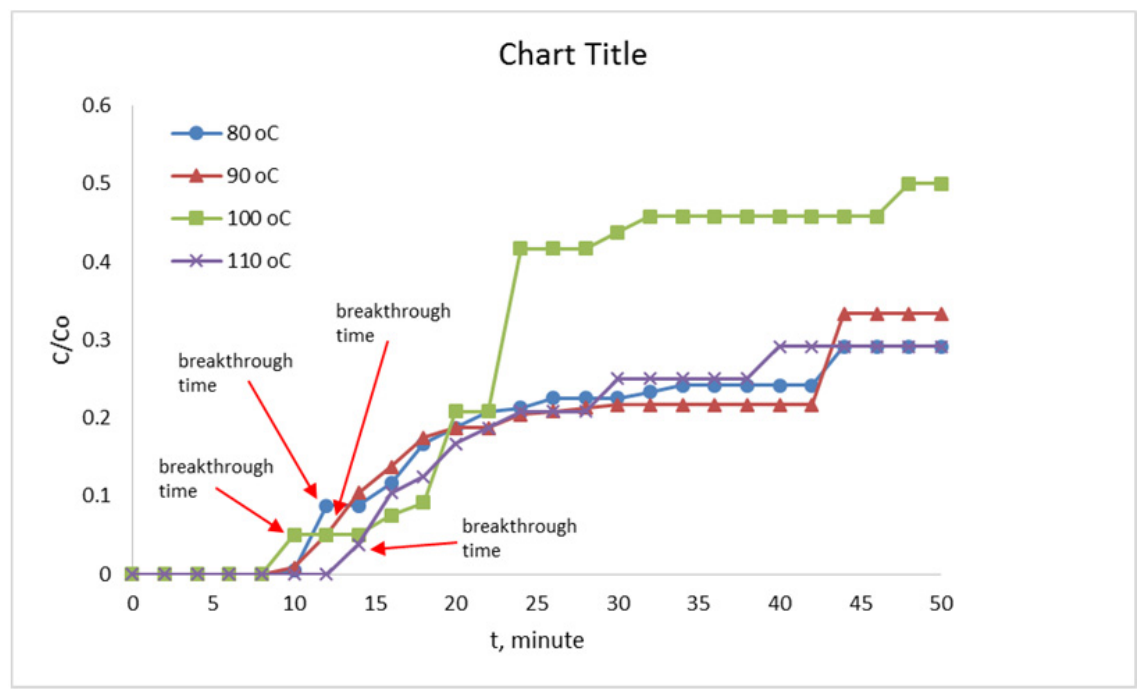

Figure 10. Breakthrough time curve in adsorption process with the ethanol content of feed is $76 \% \mathrm{v} / \mathrm{v}$ and feed plate in distillation process is the $15^{\text {th }}$ plate 
In the above figures, $\mathrm{C}$ is defined as the water content of effluent (anhydrous ethanol) from the adsorption packed column, while Co is defined as the water content of feed (ethanol distillate) that is entering the adsorption packed column. The ratio of $\mathrm{C} / \mathrm{Co}$ at a value of 1 thus shows a condition of saturated molecular sieve $3 \AA$ adsorbent. Breakthrough time is defined as time duration that is required by the effluent from the adsorption column to reach a minimum ethanol concentration of $99.5 \% \mathrm{v} / \mathrm{v}$. This means a longer breakthrough time will give a longer time period for the molecular sieve $3 \AA$ adsorbent to reach its saturated condition, which gives reduced cycle time of regeneration, and also reduced consumed energy. According to Figures 7 to 10, the optimum state for the distillation-adsorption process is obtained when the adsorption feed (ethanol content of 92\% $\mathrm{v} / \mathrm{v}$ ) temperature is at $90^{\circ} \mathrm{C}$, and feed plate location is at $14^{\text {th }}$, which gives the longest breakthrough time of 28 minutes.

\subsection{Optimization in the Feed Plate for Distillation Process and the Temperature of Feed for Adsorption Process}

In the following discussion, the total required energy to produce anhydrous ethanol is calculated by considering all the ethanol distillate from distillation process is used as a feed in the adsorption process to reach minimum ethanol purity of $99.5 \% \mathrm{v} / \mathrm{v}$. The results are the summarized in Table 1 below.

Table 1. The result of total energy consumed in the distillation-adsorption process of ethanol-water mixture

\begin{tabular}{ccccc}
\hline Plate & $\begin{array}{c}\text { Temperature } \\
\left({ }^{\circ} \mathrm{C}\right)\end{array}$ & $\begin{array}{c}\text { Breakthrough Time } \\
(\mathrm{min})\end{array}$ & $\begin{array}{c}\text { Absolute Ethanol } \\
\text { Volume }(\text { litre })\end{array}$ & $\begin{array}{c}\text { Total Energy Consumed } \\
(\mathrm{kJ} / \mathrm{kg} \text { etanol abs })\end{array}$ \\
\hline $12^{\text {th }}$ & 80 & 22 & 0.26 & 32915 \\
& 90 & 8 & 0.16 & 54504 \\
& 100 & 10 & 0.17 & 54037 \\
$13^{\text {th }}$ & 110 & 8 & 0.14 & 60560 \\
& 80 & 26 & 0.47 & 20431 \\
& 90 & 20 & 0.47 & 20464 \\
$14^{\text {th }}$ & 100 & 8 & 0.18 & 54282 \\
& 110 & 14 & 0.20 & 50174 \\
& 90 & 18 & 0.22 & 85072 \\
& 90 & 28 & 0.68 & 18691 \\
$15^{\text {th }}$ & 100 & 22 & 0.64 & 19900 \\
& 110 & 8 & 0.38 & 35476 \\
& 90 & 10 & 0.12 & 116199 \\
& 100 & 8 & 0.16 & 76823 \\
& 110 & 8 & 0.13 & 75328 \\
\end{tabular}

\section{Conclusion}

It was found that the optimum operating condition in distillation process using 16 trays occured when the feed of distillation process through the $14^{\text {th }}$ plate, whereas for the adsorption process using molecular sieve $3 \AA$ adsorbent is at adsorption feed temperature of $90^{\circ} \mathrm{C}$ with 28 minutes breakthrough time. At such particular condition, the total energy required for distillation-adsorption process to produce anhydrous ethanol $(99.5 \% \mathrm{v} / \mathrm{v})$ is found to be at its lowest energy, i.e. $18691 \mathrm{~kJ} / \mathrm{kg}$ of absolute ethanol.

\section{Acknowledgments}

The authors would like to thank the Sepuluh Nopember Institute of Technology (ITS) and the Indonesian Directorate General of Higher Education (DIKTI) for the financial supports, under the financial scheme of BOPTN ITS with contract number of 016452.23/IT2.7/PN.01.00/2014 and 003246.159/IT2.11/PN.08/2015.

\section{References}

Al-Asheh, S., Banat, F., \& Al-Lagtah, N. (2004). Separation of ethanol-water mixtures using molecular sieves and biobased adsorbent. Chemichal Engineering Research and Design, 82(A7), 855-864. http://dx.doi.org/10.1205/0263876041596779

Chen, W. C., Sheng, C. T., Liu, Y. C. Chen, W. J., Huang, W. L., Chang, S. H., \& Chang, W. C. (2014). Optimizing the efficiency of anhydrous ethanol purification via regenerable molecular sieve. Applied Energy, 135, 483-489. http://dx.doi.org/10.1016/j.apenergy.2014.08.112 
Gupta, A., \& Verma, J. P. (2015). Sustainable bio-ethanol production from agro-residues: A review. Renewable and Sustainable Energy Reviews, 41, 550-567. http://dx.doi.org/10.1016/j.rser.2014.08.032

Jan Baeyens, J., Kang, Q., Appels, L., Dewil, R., Yongqin Lv, Y., \& Tan, T. (2015). Challenges and opportunities in improving the production ofbio-ethanol. Progress in Energy and Combustion Science, 47, 60-88. http://dx.doi.org/10.1016/j.pecs.2014.10.003

Kaminski, W., Marszalek, J., \& Ciolkowska, A. (2008). Renewable energy source-Dehydrated ethanol. Chemical Engineering Journal, 135, 95-102. http://dx.doi.org/10.1016/j.cej.2007.03.017

Kumar, S., Singh, N., \& Ram Prasad, R. (2010). Anhydrous ethanol: A renewable source of energy. Renewable and Sustainable Energy Reviews, 14, 1830-1844. http://dx.doi.org/10.1016/j.rser.2010.03.015

McCabe, W. L., Smith, J. C., \& Harriot, P. (2001). Unit Operation of Chemical Engineering. New York: McGraw-Hill Book Company.

Periyasamy, S., Venkatachalams S., Ramasamy S., \& Srinivasan V. (2009). Production of bio-ethanol from sugar molasses using Saccharomyces Cerevisiae. Modern Applied Journal, 3(8), 32-37. http://dx.doi.org/10.5539/mas.v3n8p32

Simo, M., Sivashanmugam, S., Brown, C. J., \& Hlavacek, V. (2009). Adsorption/Desorption of Water and Ethanol on 3A Zeolite in Near-Adiabatic Fixed Bed. Industrial \& Engineering Chemistry Research, 48, 9247-9260. http://dx.doi.org/ 10.1021/ie900446v

Sowerby, B., \& Crittenden, B. D. (1988). An experimental comparison of type A molecular sieves for drying the ethanol-water azeotrope. Gas Separation \& Purification, 2(2), 77-83. http://dx.doi.org/10.1016/0950-4214(88)80016-1

Syeda, S. R., Afacan, A., \& Chuang K. T. (2007). A Fundamental Model for Prediction of Sieve Tray Efficiency. Chemical Engineering Research and Design, 85(2), 269-277. http://dx.doi.org/10.1205/cherd06111

Van Winkle, M. (1967). Distillation. New York : McGraw-Hill Book Company.

Viswanathan, J., \& Grossmann, I. E. (1993). Optimal feed locations and number of trays for distillation columns with multiple feeds. Industrial \& Engineering Chemistry Research, 32(11), 2942-2949. http://dx.doi.org/ 10.1021/ie00023a069

Wang, Y., Gong, C., Sun., J., Gao, H., Zheng, S., \& Xu, S. (2010). Separation of Ethanol/Water Azeotrope using Compound Starch-based Adsorbent. Bioresource Technology, 101(15), 6170-6176. http://dx.doi.org/ 10.1016/j.biortech.2010.02.102

Zuiderweg, F. I. (1982). Sieve Trays: A View on the state of the art. Chemical Engineering Science, 37(10), 1441-1464. http://dx.doi.org/10.1016/0009-2509(82)80001-8

\section{Copyrights}

Copyright for this article is retained by the author(s), with first publication rights granted to the journal.

This is an open-access article distributed under the terms and conditions of the Creative Commons Attribution license (http://creativecommons.org/licenses/by/3.0/). 